\title{
IMPLEMENTASI E-MUSEUM DR. AK. GANI PALEMBANG
}

\author{
Shinta Puspasari'1), Luis Marnisah²) \\ 1)Teknik Informatika Fakultas Ilmu Komputer, Universitas Indo Global Mandiri \\ 2)Ekonomi Manajemen Fakultas Ekonomi, Universitas Indo Global Mandiri \\ Jalan Jendral Sudirman No.629 Palembang 30129 \\ Email : $\underline{\text { shinta@uigm.ac.id }}{ }^{1}$, luis@uigm.ac.id $^{2}{ }^{2}$
}

\begin{abstract}
ABSTRAK
Aplikasi berbasis Web untuk pengelolaan koleksi museum dr.AK.Gani berupa e-Museum yang sekaligus dapat berperan sebagai ruang pamer virtual. E-Museum dimanfaatkan untuk pengelolaan informasi mengenai koleksi yang dimiliki oleh museum dr.AK.Gani berupa buku-buku, foto, serta benda peningggalan Pahlawan Nasional MayJen (Purn) dr.AK.Gani. Sosialisasi aplikasi telah dilakukan dengan berbagai cara, yatu Sosialisasi pada Pameran Sriwijaya Expo di bulan Agustus 2019 serta publikasi lewat media massa. Desain perangkat informative yang didesain sebagai media penyampaian informasi yang lebih menarik telah dibuat dan menjadi alternative bagi pengunjung museum untuk mendapatkan inforasi terkait museum. E-Museum telah diujicobakan kepada kepala museum serta pengguna umum dan diketahui bahwa aplikasi dapat berfungsi dengan baik dan pengguna menjadi lebih tahu mengenai museum dr.AK.Gani serta tertarik untuk dating ke museum. Aplikasi ini diharapkan dapat meningkatkan layanan dan memudahkan pengunjung mengakses informasi mengenai museum dr.AK.Gani sehingga tertarik untuk datang ke museum dan berdampak pada peningkatan layanan dan ekonomi museum dr.AK.Gani.
\end{abstract}

Kata kunci : e-Museum, dr.AK.Gani, manajemen koleksi

\section{PENDAHULUAN}

Museum dr.AK. Gani berlokasi di Jalan Jl. MP. Mangkunegara No.1F, Sukamaju, Ilir Tim. II, Kota Palembang, Sumatera Selatan 30961. Museum Pahlawan Nasional Mayor Jenderal TNI (Purn.) dr. A.K. Gani berdiri pada 2004 dan dikelola oleh Yayasan Hj. R.A. Masturah A.K. Gani. Saat ini, di antara beberapa orang keluarga A.K. Gani hanya dua orang yang peduli pada sejarah dan museum, yaitu G.I. Priyanti Gani sebagai Direktur Museum H. Iskandar Gani sebagai Ketua Yayasan. Museum menempati bekas rumah pribadi dr. A.K. Gani yang dibangun pada 1956 (Gambar 1). Museum buka setiap hari dengan rata-rata pengunjung kurang lebih 10 pengunjung dari berbagai kalangan, pelajar mahasiswa, militer, politisi, dan lainnya. Hal ini dikarenakan Mayjen. dr. AK. Gani merupakan Pahlawan Nasional yang pernah menjadi Residen Palembang pertama dan Gubernur Sumatera Selatan pertama. Selain di dunia medis, ia juga aktif di kemiliteran. Ia adalah tokoh pertempuran lima hari lima malam di Palembang. Semasa pemerintahan Presiden Soekarno, ia merintis pembangunan Jembatan Ampera dan pabrik Pupuk Sriwijaya. Atas jasanya di bidang militer pula lah, sehingga namanya diabadikan sebagai nama Rumah Sakit Militer dr. AK. Gani di Palembang. Pada Tahun 2007, dr. AK. Gani dianugrahi gelar Pahlawan Nasional. 
Selain bidang militer, dr.AK. Gani menguasai bidang Kedokteran, Ekonomi, dan Politik. Ini dibuktikan dengan berbagai koleksi buku berkujumlah kurang lebih 2000 buku yang masih tersimpan dalam museum namun tidak terindeks dengan baik dan rentan kerusakan dikarenakan perawatan dan pengelolaan yang profesional. Saat observasi awal, diketahui bahwa pengelolan koleksi masih dilakukan secara manual dan ketika koleksi diambil dari dalam lemari penyimpan diketahui bahwa koleksi mulai terlihat mengalami kerusakan dan rapuh serta berdebu. Sejumlah koleksi hanya ditampilkan dalam lemari tanpa adanya keterangan atau deskripsi mengenai koleksi tersebut padahal koleksi yang banyak dan tidak adanya pemandu khusus di museum menyebabkan museum tidak menarik dan kurang informatif. Pengunjung kesulitan untuk mengakses informasi mengenai koleksi, sedangkan jika diakses langsung ke koleksi menyebabkan kerusakan koleksi yang sangat berharga dan bernilai sejarah.

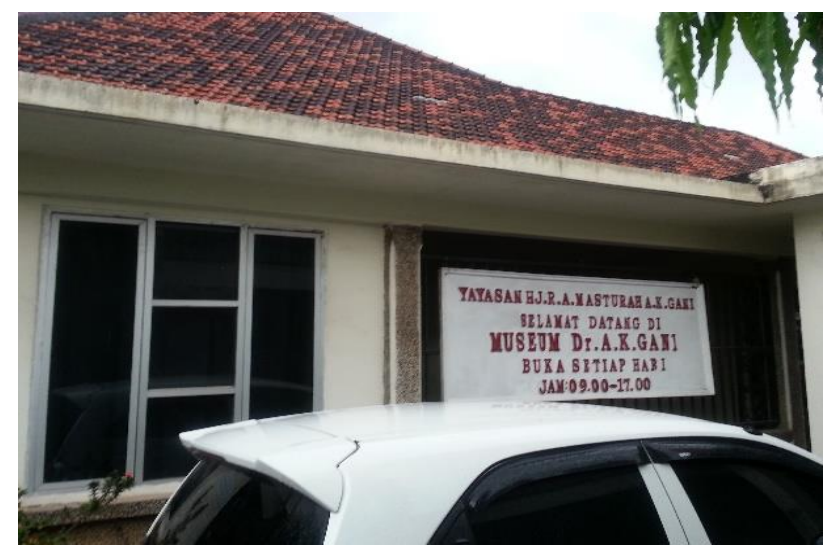

Gambar 1. Gedung Museum dr.AK.Gani

Museum dr.AK. Gani sebagai Museum Non Profit yang didirikan oleh yayasan [1] sehingga pengelolaan museum yang didanai oleh Yayasan menyebabkan tidak banyak yang dapat dilakukan oleh yayasan untuk menjaga kelestarian koleksi. Keberadaaanya pun mulai terancam dikarenakan kerusakan karena tidak terawat dan dikelola dengan baik akibat akses langsung yang sering dilakukan oleh pengunjung untuk mendapatkan informasi lengkap dari koleksi. Termasuk koleksi kain-kain berharga milik dr. AK. Gani dan istrinya yang sampai saat ini masih tersimpan dalam lemari namun terancam rusak akibat selalu dipegang oleh pengunjung. Padahal ada aturan permuseuman untuk menyentuh koleksi tidak dapat dilakukan secara sembarang guna menjaga kualitas dan kelestariannya. Koleksi melibatkan serangkaian proses - yang menjadi lebih efisien dengan adanya teknologi komputer dan komunikasi- yang menghimpun informasi, mengkoordinasikan komunikasi, menyusun kebijakan, evaluasi dan perencanaan [2]. Karena itu, sebuah solusi berbasis TIK yaitu eMuseum. E-museum adalah kumpulan gambar, dokumen suara, teks dokumen, dan video dari sejarah, ilmiah atau kepentingan budaya yang direkam secara digital dan dapat diakses melalui media elektronik. E-museum juga sering disebut sebagai museum virtual, museum elektronik, dan museum digital. Munculnya e-museum telah membuat koleksi museum lebih mudah diakses dari mana saja dan kapan saja. E-museum telah membuat koleksi museum lebih mudah diakses dari mana saja dan kapan saja [3].

\subsection{Permasalahan Mitra}

1. Pengelolaan atau manajemen Koleksi yang masih manual, tidak adanya dokumen inventaris koleksi, tidak adanya katalog untuk pengindeksan buku, pencatatan pengunjung secara manual, menyebabkan kesulitan dalam pencarian informasi mengenai koleksi museum, serta akibat akses manual pada koleksi berdampak pada kelestarian koleksi karena rentan mengalami kerusakan bahkan hilang. Terlihat dari sampel koleksi yang ditunjukkan saat observasi ke lokasi museum dan buku catatan pengunjung yang tidak terdokumentasi dengan baik

2. Minimnya informasi yang menyertai koleksi serta penyajian informasi yang tidak mengikuti perkembangan Teknologi Informasi terkini menyebabkan ketidaktertarikan pengunjung untuk berlama-lama menggali mempelajari sejarah dan tidak menarik pengunjung baru untuk turut 
berwisata sejarah di museum dr.AK.Gani. Padahal museum tersebut memiliki potensi secara ekonomi jika layanan ditingkatkan dan sekaligus berdampak pada kelestarian sejarah Nasional.

\subsection{Tujuan Program Kemitraan Masyarakat}

1. Membangun museum virtual (e-Museum) dr.AK.Gani untuk pengelolaan data koleksi museum.

2. Mendesain Standing Banner Informatif dan menarik yang lebih kekinian dibandingkan informasi format teks yang dicetak di atas kertas dan lebih tahan terhadap kondisi lembab atau debu yang dapat merusak atau menghilangkan informasi sehingga dapat lebih Informatif dan Menarik mengenai Koleksi Secara Umum yang dapat menarik minat pengunjung dan menarik pengunjung baru untuk datang mempelajari sejarah dr. AK. Gani.

\subsection{Manfaat Program Kemitraan Masyarakat}

Diharapkan dapat meningkatnya kualitas layanan mitra, Museum dr.AK.Gani, yang berpotensi pada peningkatan jumlah pengunjung dan perekonomian untuk mendukung pengelolaan dan pelestarian koleksi museum.

\section{METODE PELAKSANAAN PENGABDIAN}

Kegiatan yang akan dilaksanakan dikategorisasikan menjadi 2 (dua) kegiatan utama merujuk pada solusi permasalahan yang diajukan dalam kegiatan ini, yaitu :

1. Merancang Manajemen Koleksi Museum

2. Merekayasa aplikasi e-museum untuk optimalisasi manajemen koleksi museum

Untuk itu disusun tahapan-tahapan pelaksanaan kegiatan seperti Gambar 2 berikut:

\section{Merancang Manajemen Koleksi Museum}

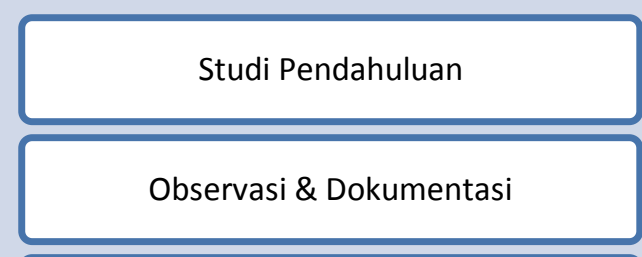

Analisis Strategi Manajemen Koleksi Museum

Pengumpulan Informasi Koleksi
Merekayasa Aplikasi e-Museum

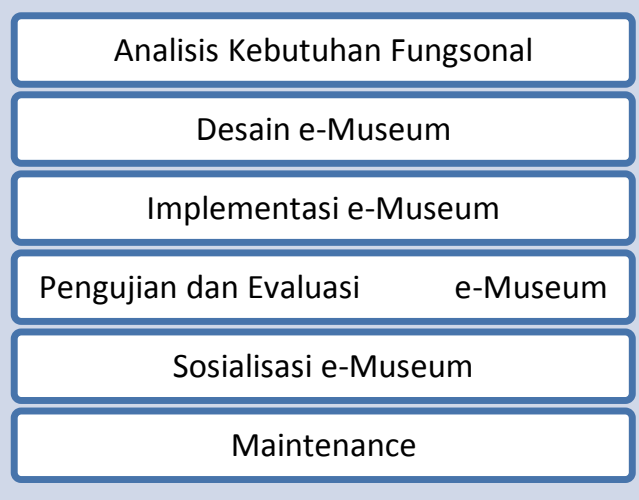

Gambar 2. Metode Pelaksanaan Kegiatan

\subsection{Studi Pendahuluan}

Pada tahapan ini dilakukan penelusuran terhadap permasalaha mitra dan analisis situasi serta solusi terkait dengan kegiatan yang diusulkan untuk dilaksanakan dalam mencapai target solusi permasalahan dan luaran program kemitraan. Studi literatur juga dilakukan berupa penelusuran sumber literatur primer dan sekunder berupa buku, jurnal, dan dokumen peraturan mengenai permuseuman Nasional.

\subsection{Pengumpulan Data}

Pengumpulan data primer maupun sekunder dilakukan dengan metode berikut:

1. Wawancara

Wawancara ialah proses komunikasi atau interaksi untuk mengumpulkan informasi dengan tanya jawab antara peneliti dengan informan [4]. Wawancara dilakukan untuk mengetahui permasalahan, 
solusi, dan strategi museum dalam upaya peningkatan layanan dan keberlanjutan museum dr.AK.Gani. Wawancara dengan Kepala Museum Ibu G.I Priyanti Gani dan Bapak Iskandar selaku pengelola Museum.

2. Observasi

Observasi hakikatnya merupakan kegiatan dengan menggunakan pancaindera, bisa penglihatan, penciuman, pendengaran, untuk memperoleh informasi yang diperlukan untuk menjawab masalah penelitian. Hasil observasi berupa aktivitas, kejadian, peristiwa, objek, kondisi atau suasana tertentu, dan perasaan emosi seseorang. Observasi dilakukan untuk memperoleh gambaran riil suatu peristiwa atau kejadian untuk menjawab pertanyaan penelitian [4]. Pengamatan Langsung di Museum guna mengetahui kemungkinan pelaksanaan program yang diusulkan sebagai solusi permasalahan. Perekaman data dengan instrument kamera dan pemindai digital.

3. Dokumentasi

Dokumen berupa buku koleksi didokumentasikan ulang secara digital serta beberapa sumber dokumen yang menjadi bagian koleksi direka ulang untuk tujuan pelestarian dan peremajaan.

Setelah data terkumpul selanjutnya akan dilakukan rekayasa aplikasi e-Museum berdasarkan data yang ada. Data tersebut akan diolah dan dianalisa untuk mengetahui kebutuhan fungsionalitas aplikasi eMuseum.

\subsection{Rekayasa Aplikasi e-Museum}

Aplikasi eMuseum dr.AK.Gani direkayasa dengan menerapkan tahapan berikut [6]:

1. Analisis Kebutuhan Fungsional e-Museum

Melakukan analisis kebutuhan fungsi-fungsi yang dapat dilakukan oleh e-museum terkait dengan pengelolaan koleksi museum maupun penyajian informasi koleksi museum. Analisis yang dilakukan menghasilkan model kebutuhan fungsional perangkat lunak yang siap untuk didesain.

2. Desain e-Museum

Perancangan basis data dan antarmuka e-museum dilakukan pada tahapan ini dengan input kegiatan berupa model hasil analisis kebutuhan fungsional yang telah dihasilkan pada tahapan sebelumnya.

3. Implementasi e-Museum

Implementasi berupa kegiatan pengkodean hasil desain e-museum berupa desain basis data dan antarmuka pada tahapan sebelumnya yang diterjemahkan dalam dalam Bahasa pemrograman Hypertext Processor (PHP) untuk membangun aplikasi berbasis website hingga dihasilkan sebuah Teknologi Tepat Guna berupa Prototipe Aplikasi e-Museum.

4. Pengujian dan Evaluasi e-Museum

Pengujian dilakukan dengan menggunakan kuseioner untuk mengetahui apakah e-Museum sudah efektif dan efisien, sedangkan evaluasi dilakukan dengan melakukan pengukuran menggunakan alat berupa kuesioner untuk mengukur pemanfaatan e-Museum dan metode pelaksanaan kegiatan yang telah dilakukan.

5. Sosialisasi e-Museum

Sosialisasi dilakukan baik melalui media massa cetak lokal maupun lewat seminar lokal dan internasional. Selain itu, diusulkan hak cipta terhadap draf Buku dan prototype aplikasi e-Museum.

\section{HASIL DAN PEMBAHASAN}

Program kemitraan masyarakat ini dilaksanakan sejak bulan Maret 2019 hingga September 2019 dengan hasil kegiatan sebagai berikut:

1. Pengumpulan Data

a. Wawancara

Telah dilakukan wawancara dengan Kepala Museum dan pengelola museum mengenai permasalahan dan solusi yang disepakati untuk diimplementasikan di Museum dr.AK.Gani (Gambar $3)$. 

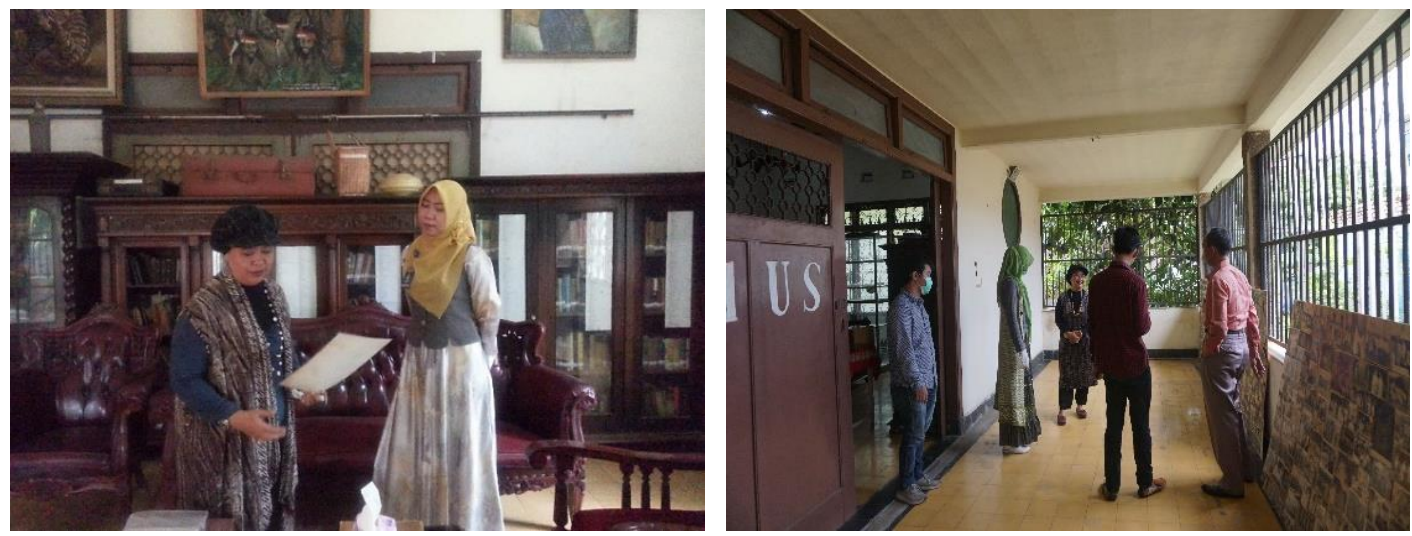

Gambar 3. Wawancara dengan pengelola dan kepala Museum dr.AK.Gani

b. Observasi

Pengamatan langsung pada Museum dr.AK Gani untuk mengetahui situasi dan kondisi terkini bangunan dan koleksi museum (Gambar 4). Perekaman dilakukan dengan alat kamera dan pemindai digital
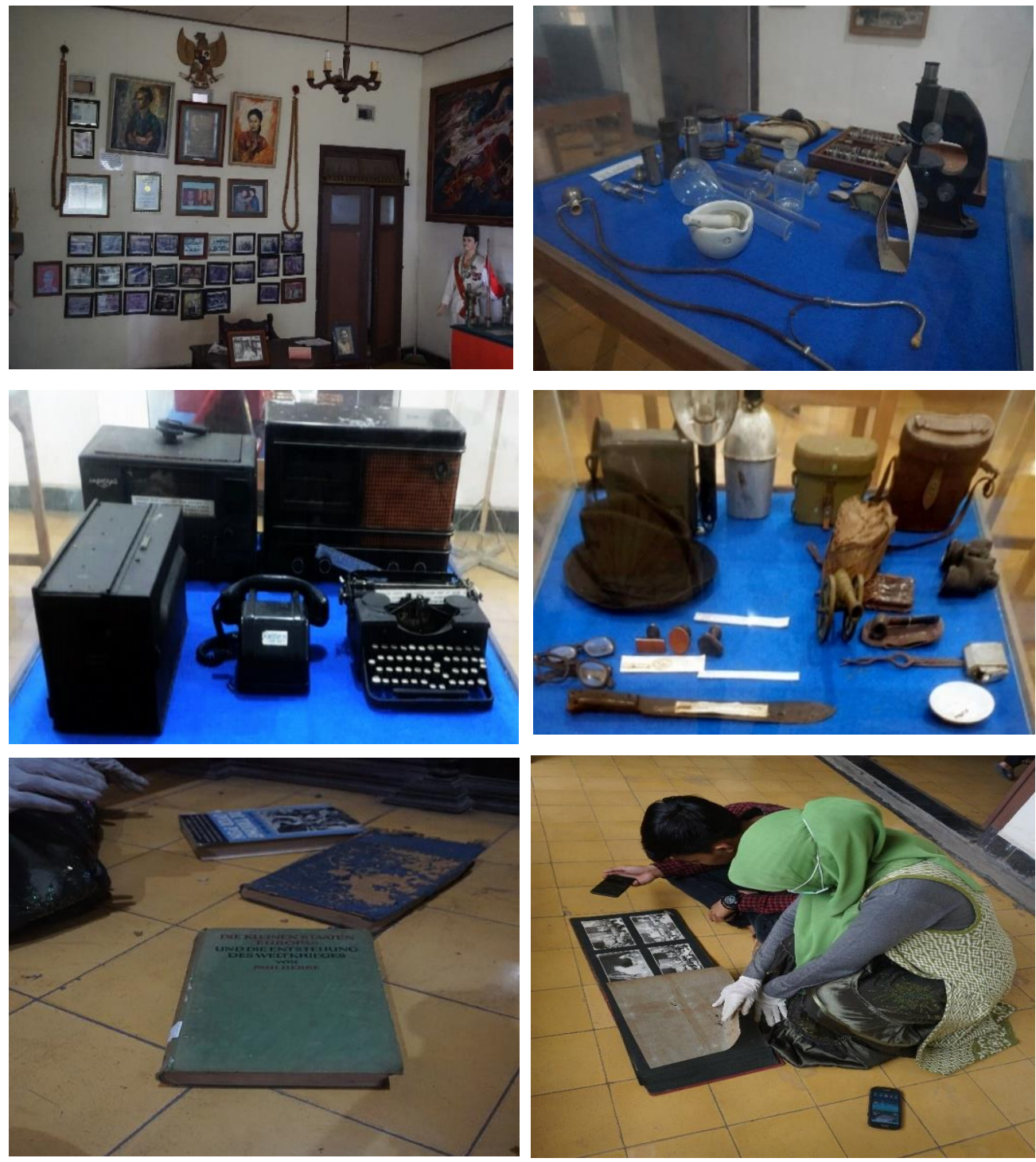

Gambar 4. Hasil Observasi 
c. Dokumentasi

Dokumen berupa koleksi buku serta sejumlah foto-foto dan dokumen bersejarah didigitalisasi (Gambar 5) dan diolah untuk dijadikan bahan rekayasa e-Museum serta desain banner informatif. Sejumlah 700 (Tujuh ratus) Data buku koleksi Museum berhasil dikumpulkan. Beberapa diantaranya seperti Tabel 1 berikut,

Table 1. Sampel Koleksi Buku Museum dr.AK.Gani

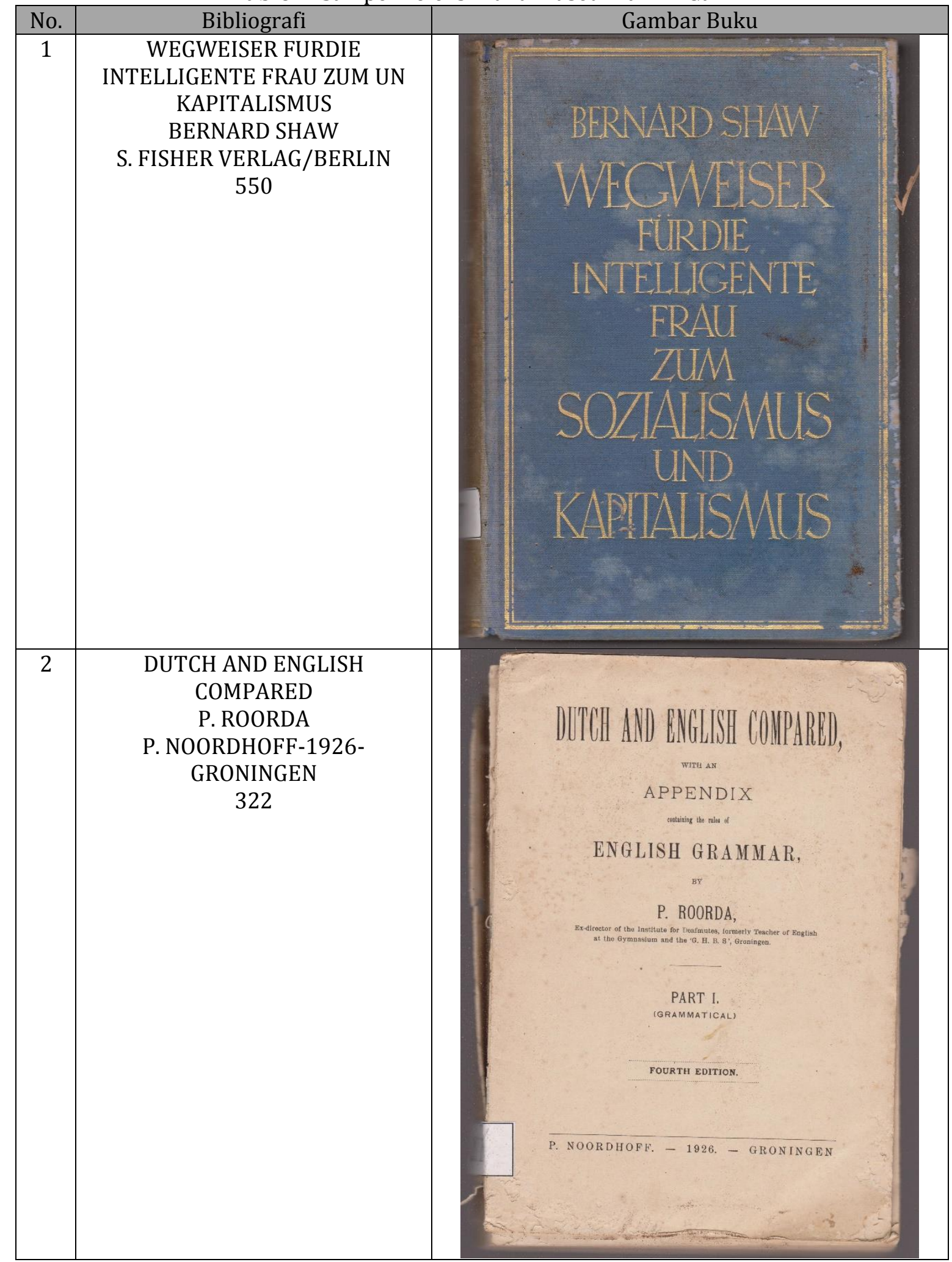




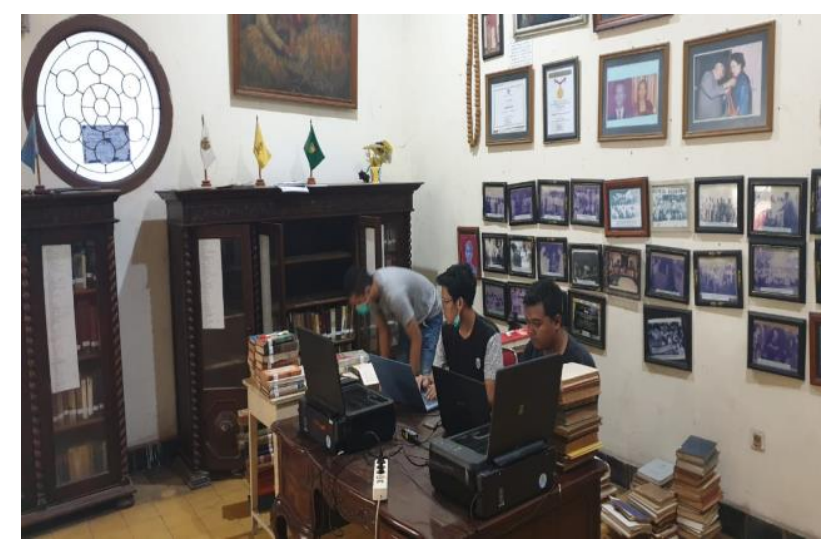

(a)
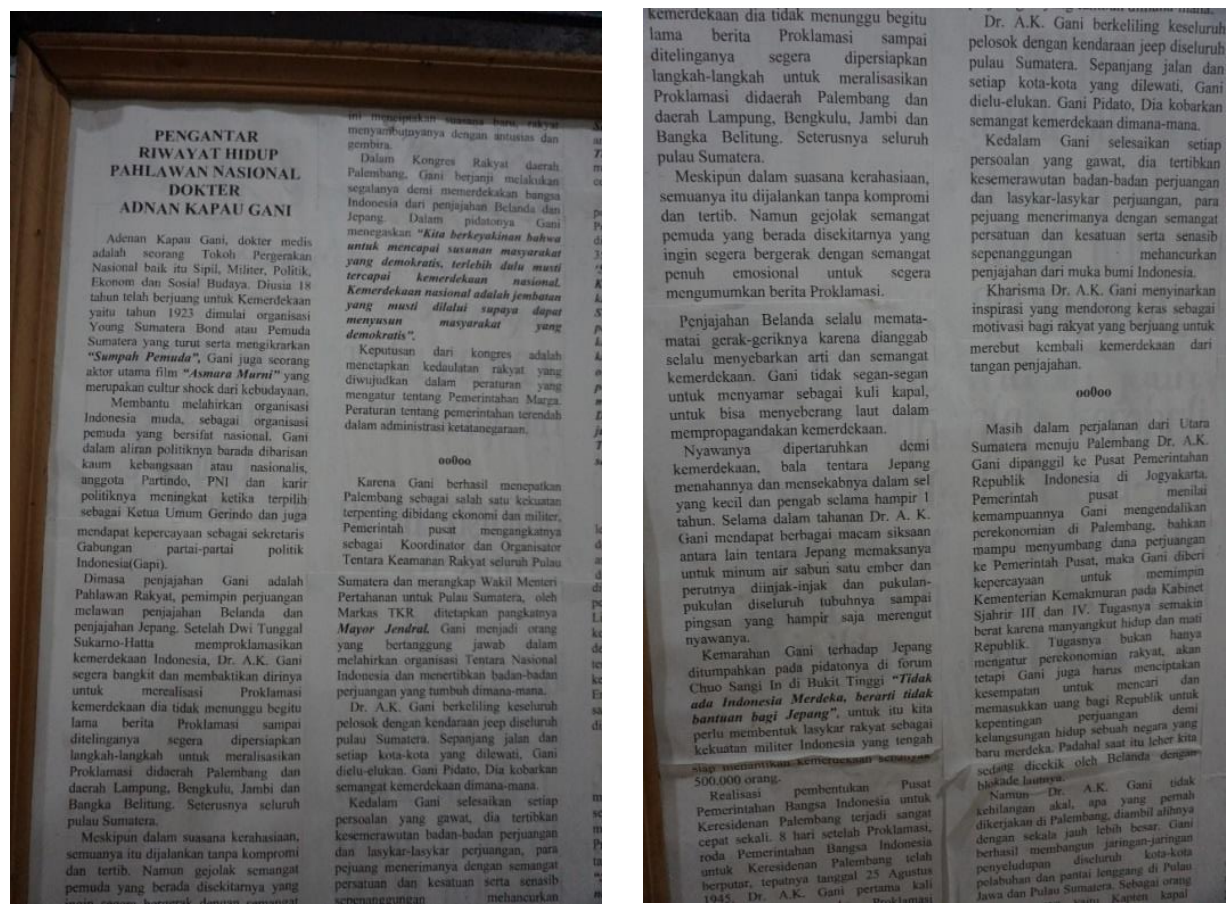

(b)

Gambar 5. a,b. Hasil Dokumentasi

2. Rekayasa Aplikasi e-Museum

Berdasarkan hasil pengumpulan data dan analisis kebutuhan e-Museum, maka dibuatlah rancangan antar muka e-museum dr.AK.Gani,

a. Rancangan Antar Muka

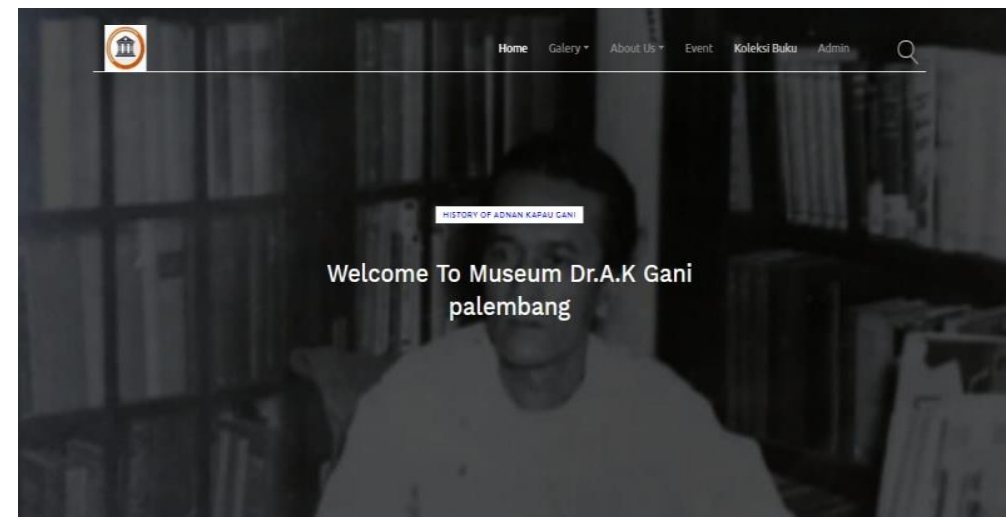

(a) 


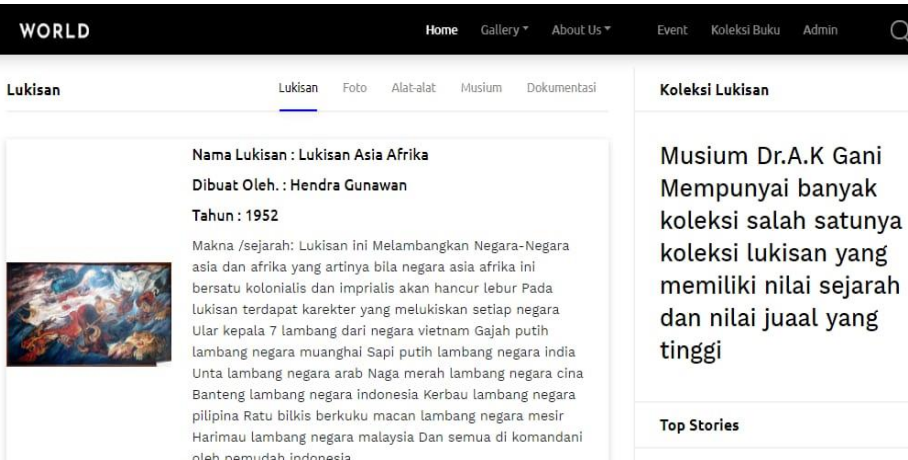

(b)

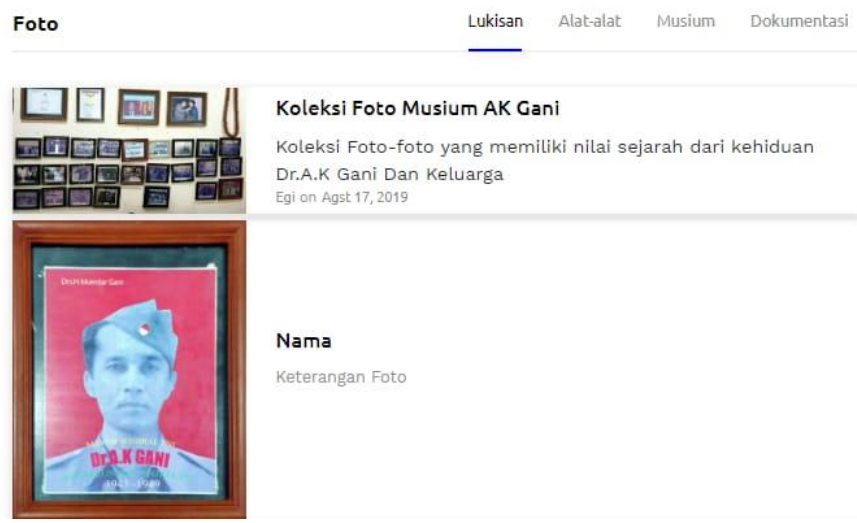

(c)

Gambar 6. Desain Antar muka prototipe e-Musium

b. Pengujian Aplikasi

Pengujian dilakukan hingga pengguna aplikasi. Untuk itu dilakukan penyebaran questioner untuk evaluasi eMuseum dengan menggunakan metode pengujian System Usability Scale. Tujuannya untuk mengukur kinerja aplikasi dari sisi pengguna serta manfaat aplikasi bagi peningkatan layanan museum dr.AK.Gani.

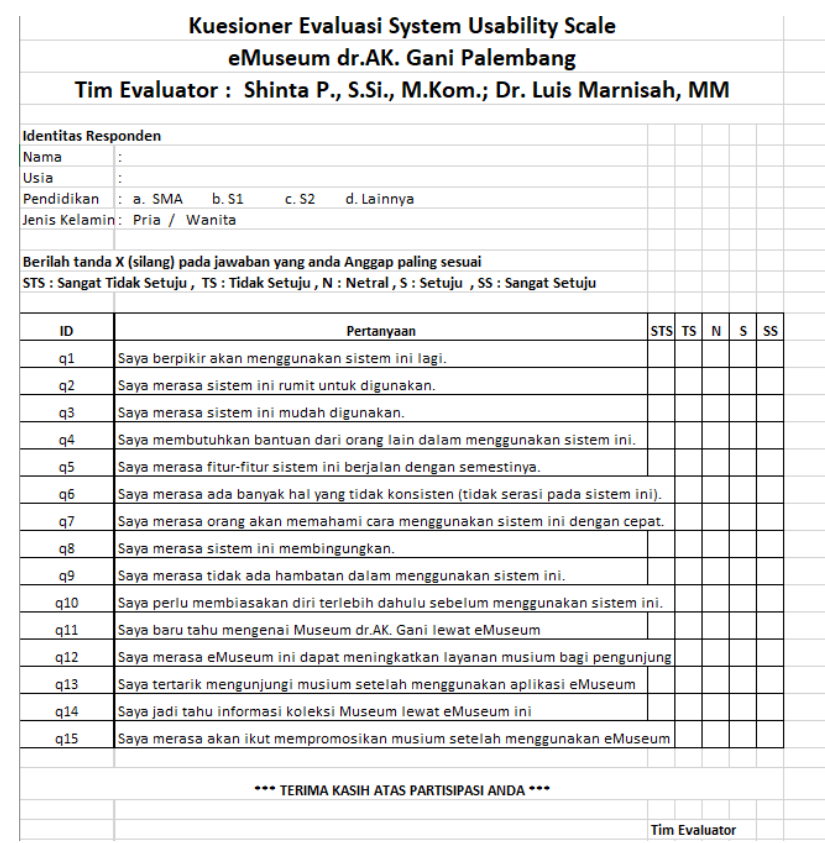

Gambar 7. Instrumen Pengujian e-Museum 


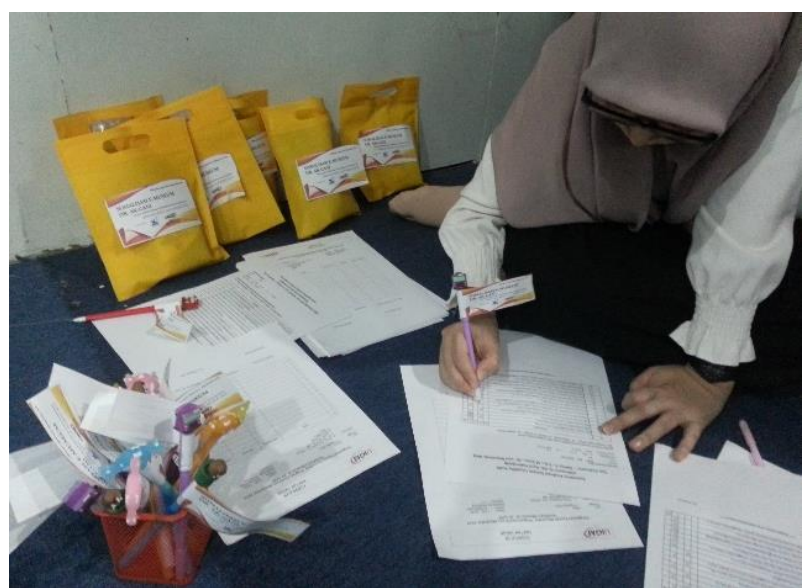

Gambar 8. Pengisian Kuesioner oleh responden

c. Sosialisasi e-Museum

Sosialisasi e-Museum dr.AK.Gani di Pameran Sriwijaya Expo, Dekranasda jakaaring, yang diselenggarakan oleh pemerintah Provinsi Sumatera Selatan, 14-19 Agustus 2019.
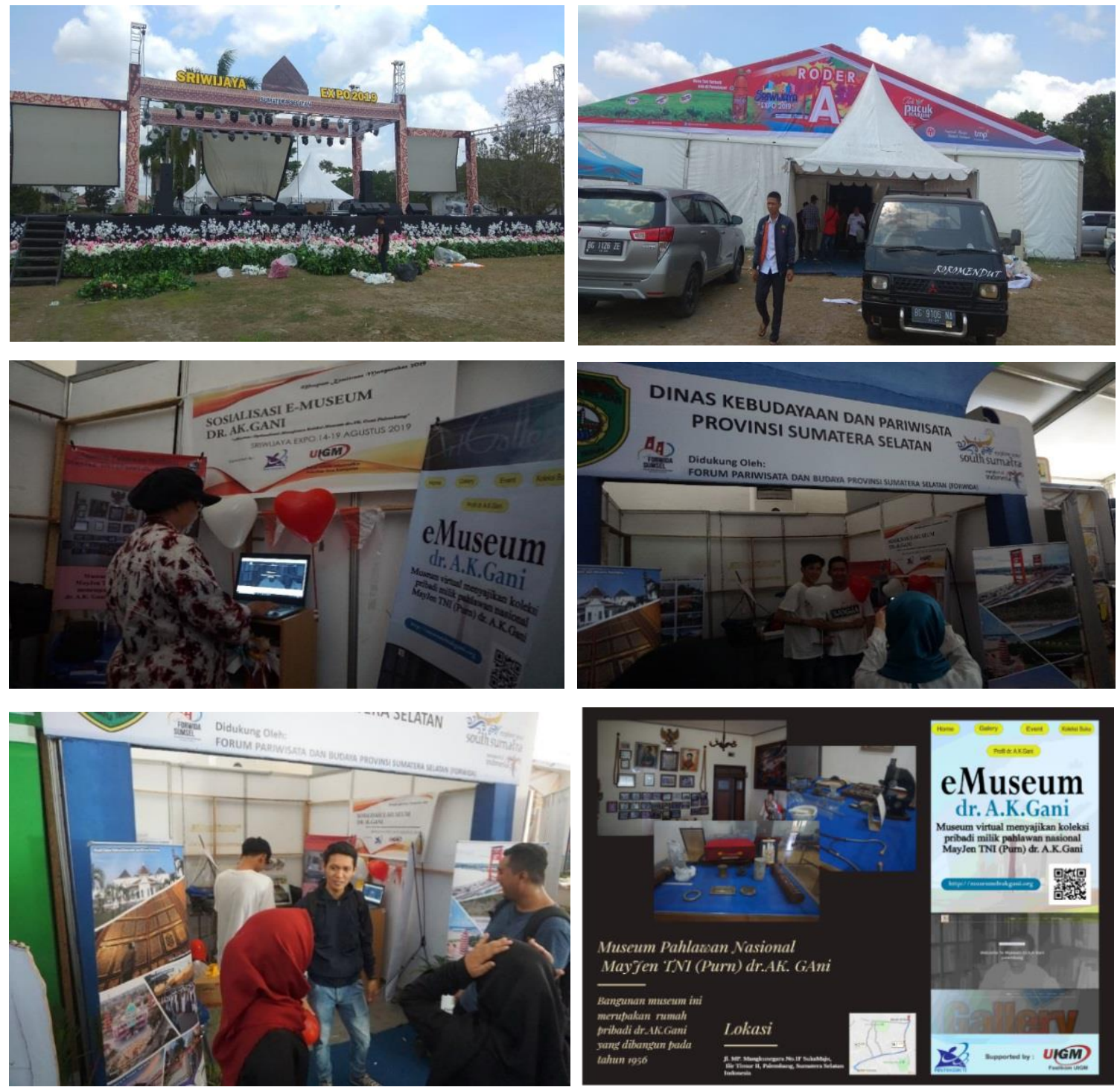

Gambar 9. Sosialisasi e-Musium di Pameran Sriwijaya Expo 


\section{Desain Banner Informatif}

Saat ini telah didesain 2(dua) standing banner untuk kelengkapan Sosialisasi e-Musium dr.AK.Gani di Pameran Sriwijaya Expo, Dekranasda jakaaring, yang diselenggarakan oleh pemerintah Provinsi Sumatera Selatan, 14-19 Agustus 2019. Selanjutnya akan didesain lagi 2(dua) Poster Banner untuk dipasang di dinding Museum,
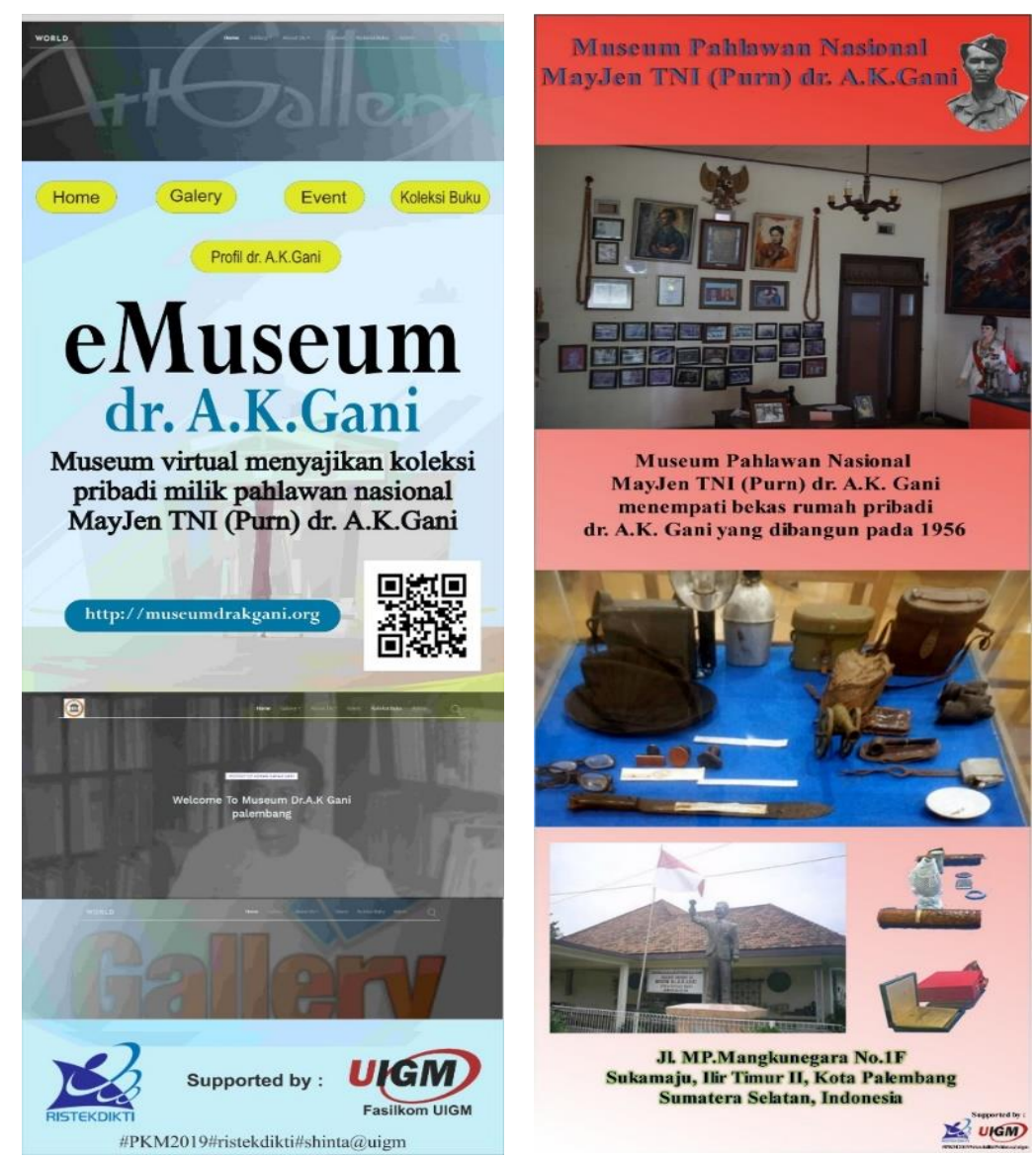

Gambar 10. Desain Standing Banner e-Museum

\section{KESIMPULAN}

Kegiatan Program kemitraan Masyarakat ini berhasil membangun eMuseum untuk pengelolaan koleksi Museum dr.AK.Gani Palembang. Diharapkan dengan memanfaatkan museum virtual tersebut dapat meningkatkan layanan museum yang berdampak pada meningkatnya kunjungan dan pendapatan museum guna mendukung kelestarian koleksi dan keberadaan museum.

\section{UCAPAN TERIMA KASIH}

Ucapan terimakasih diberikan kepada Mitra Program Kemitraan Masyarakat ini yaitu Museum dr.AK.Gani Palembang yang telah memberikan dukungan serta DRPM Kemristek DIKTI yang telah memberikan Hibah kegiatan sehingga berujung pada kegiatan Pengabdian Kepada Masyarakat ini.

\section{DAFTAR PUSTAKA}

[1] Rohanda \& S. Agustina, "Manajemen Koleksi (Collection Management) Kebijakan Pengembangan Koleksi Perpustakaan Perguruan Tinggi", Jurnal Iqra Vol.4 No.1 Mei 2010.

[2] Triana Santi, "Manajemen Koleksi (Collection Management) Kebijakan Pengembangan Koleksi Perpustakaan Perguruan Tinggi", Jurnal Iqra Vol.4 No.1 Mei 2010. 
[3] Ulce Oktrivia, "e-Museum: Komodifikasi Informasi Koleksi Museum", Jurnal Naditira Widya Vol.8 No.1 Tahun 2014.

[4] Yunus, Hadi Sabari. Metodologi Penelitian Wilayah Kontemporer. Yogyakarta: Pustaka Pelajar. 2010.

[5] Bungin, M. Burhan. Penelitian Kualitatif: Komunikasi, Ekonomi, Kebijakan Publik, dan Ilmu Sosial Lainnya. Jakarta: Kencana Prenada Media Group. 2007.

[6] Pressman, Roger.S. Rekayasa Perangkat Lunak. Buku 1. Edisi 7.Penerbit Andi. 2012. 